\title{
7. ENTRE LOS EXTREMOS: LA RELIGIÓN
}

\section{INTRODUCCIÓN}

Como algo que puede ayudar a la reflexión teológica, pongo aquí las meditaciones sobre el fenómeno religioso de un no creyente, Walter Kaufmann, el cual, sin embargo, resulta muy aleccionador, ya que nos hace pensar en que, más allá de las apologéticas racionalistas en las que hemos caído, por obra de la modernidad, hay que tomar en cuenta las razones del corazón, como hacía Pascal, pero sin caer en el emotivismo de la posmodernidad. Casi señala hacia una postura analógica, como la del propio Pascal, que consiste en atender a la razón, pero más al corazón, a la mística más que a la filosofía de la religión en nuestro trabajo de fundamentar la teología, o de hacer teología fundamental. Como desconfía de la filosofía de la religión, Kaufmann hace una suerte de teología, de teología negativa, más precisamente. Pero la analogía nos enseña, como a santo Tomás, a ir más allá, hacia algo positivo que podamos decir, aunque solo sea aproximativo o proporcional. Sin caer en la teología puramente positiva, nos hace salir de la teología meramente negativa.

Hay que aprender a vivir entre los extremos. Ordinariamente, buscamos el lugar seguro, como las cosas tienden a su lugar natural. Pero la vida misma es extremosa, a veces, conflictiva, y tenemos que lograr el equilibrio difícil entre los opuestos. Equilibrio siempre 
frágil, pero continuo. Eso lo conquistamos con la sensibilidad analógica, con la apertura a la oscilación, al balanceo.

Tal es la noción de prudencia o phrónesis, detrás de la cual se encuentra la de la analogía. Es colocarse en medio, entre los extremos del univocismo y el equivocismo. Por ejemplo, en el caso de la religión, entre el puro emotivismo de la experiencia mística, que tiene que ser discernida, y el mero racionalismo de la teología, que necesita llenarse de vida, para no secarse en el formalismo. Porque la vida está en esa tensión, en un equilibrio que no es estático, sino dinámico, incluso, a veces, es trágico, pues, implica dolor, para lograr sin lograr, sin alcanzar.

\section{WALTER KAUFMANN: ENTRE EL RACIONALISMO FILOSÓFICO Y EL EMOTIVISMO RELIGIOSO}

Encuentro un caso curioso de emotivismo religioso que, sin embargo, desea equilibrarse con la razón, en Walter Kaufmann, filósofo de origen alemán, naturalizado estadounidense, del siglo XX. Me parece interesante e iluminador atender a sus disquisiciones relativas a ese ámbito.

Walter Kaufmann (1921-1980) nació en Friburgo, Alemania. Pero pasó a los Estados Unidos en 1939, huyendo de la opresión nazi. Estudió en el Williams College, donde se graduó; participó en la Segunda Guerra Mundial, en el Servicio de Inteligencia Norteamericana, y se doctoró en Harvard (1947). Enseñó en Princeton de 1947 a 1980, el año de su muerte, a los 59 años. 
Siempre estuvo muy interesado en la religión. Fue educado como luterano, pero no pudiendo creer en la Santísima Trinidad ni en la divinidad de Jesús, se hizo judío (él mismo dice que no conocía la Iglesia unitaria). Asimismo, se percató de que sus abuelos habían sido judíos. Por esa ascendencia judía tuvo que huir de Alemania. Pero también dejó el judaísmo y toda religión, en 1959, como se ve en su artículo "La fe de un hereje" (pp. 33 y ss.), de ese año.

Se destacó como estudioso de Hegel y de Nietzsche (véanse Nietzsche: Philosopher, Psychologist, Antichrist, 1950, y Hegel, 1965), al igual que del existencialismo (véase From Shakespeare to Existentialism, 1960), pero también estuvo muy interesado en la filosofía de la religión. Este último aspecto de filósofo de la religión es el que nos va a ocupar aquí.

En cuanto a Hegel, Kaufmann (1965, p. 9) lo presenta como un pensador audaz y lo defiende de otros. A Kierkegaard lo considera un pensador religioso y filósofo (1950, pp. 176-177). En cuanto a Nietzsche, lo ve como uno de los grandes (1968, pp. xx-xxi). En todos ellos sabe encontrar su aportación no solo a la filosofía, sino al pensamiento de la religión. Sobre este último tema, la religión, tiene varios libros, pero nos centraremos en su Critique of Religion and Philosophy, de 1959 (reeditada en 1972 y 1978) (Crítica de la religión y la filosofía, 1983).

En ese libro examina los argumentos para probar la existencia de Dios, desde Platón hasta la actualidad, pasando por san Anselmo, santo Tomás, Pascal, Leibniz, James, etcétera. En todos encuentra algún defecto, por lo que no pueden concluir con lo que desean. Incluso piensa que, igualmente, podrían demostrar el politeísmo, o el panteísmo, u otra cosa semejante. En todo caso, va mostrando que todos esos argumentos no prueban a Dios (1983, pp. 136 y ss.). 
Entre ellos toca el argumento de Pascal y siente algún atractivo hacia él. Es el de la famosa apuesta: si creo en Dios y existe, gano todo; si creo en Él y no existe, no habré perdido nada. Pero a Kaufmann le parece que detrás de él está el interés, una prudencia falsa, que no brota del amor y, por eso, hace al argumento insuficiente o desviado (1983, pp. 163-165).

En cuanto al discurso o lenguaje sobre Dios, proclama que todos los enunciados sobre Él son irremediablemente ambiguos. Se opone tanto a la analogía como a la simbolicidad y a la desmitificación. Por eso, denigra la teología como un intento de paralizar lo que es vivo y dinámico en fórmulas, condenadas a ser inapropiadas (1983, pp. 166 y ss.).

En cambio, y a semejanza de Bergson, lo que más le convence es la existencia de los místicos. Ellos han tenido experiencias, en las diferentes religiones. Significativamente, Kaufmann insiste en que él mismo tuvo algunas de esas experiencias, que pueden llamarse místicas. Por eso, les da tanta importancia.

Mas, por otra parte, sostiene que las experiencias místicas no son susceptibles de ser llevadas totalmente a la racionalización. Deben respetarse en su puridad. Sin embargo, no deben dejar de lado la razón, porque ella es crítica, y se la necesita para discernir si son verdaderas o falsas las experiencias o revelaciones, tanto las nuestras como las ajenas. Tal es el espíritu de la filosofía, la cual no puede reducir todo a la razón, pero debe usarla para cribar intuiciones y sentimientos. De otra manera, todo se valdría.

Kaufmann quiere, pues, evitar el relativismo extremo en la filosofía y en la religión. Si bien la razón no puede abarcar todo, en contra de Hegel, tiene que ser usada como instrumento para discernir. 
Pero Kaufmann llega a algo muy impresionante, que incluso lo coloca como un purificador de la religión, al igual que se puede decir de Nietzsche. Quiere que se preserve lo vivo y dinámico de la experiencia religiosa. Hace la genealogía de la religión; señala su origen. $\mathrm{Y}$, precisamente, lo encuentra de manera inmejorable expresado en el relato del Génesis, donde la serpiente le dice a Eva que Dios les ha prohibido comer del fruto del árbol porque serán como Él: "Seréis como dioses".

Así, Kaufmann encuentra la raíz de la religión en el deseo que tiene el hombre de ser como Dios. No tanto, o no solamente, omnipotente, omnisapiente, etcétera, sino, sobre todo, creativo y amoroso. Y conocer el secreto del bien y del mal.

En esa línea, Kaufmann critica a Kant y a Freud. A Kant porque con la razón redujo la religión a aspiración, y a Freud porque quiso acabar con esa aspiración en aras de la razón. En efecto, este último sostenía que la religión es un suplente del deseo sexual. Pero Kaufmann aduce el ejemplo de individuos y épocas enteras en las que reina el desenfreno y de ninguna manera puede decirse que estén realizados. Falta algo más.

Kaufmann va más al fondo, y me desconcierta su audacia. La religión obedece a una aspiración ontológica del hombre. Esto es muy profundo. Cuando Kaufmann habla de que el hombre tiene un oculto deseo de ser Dios, no lo hace con burla o con ironía, sino con una seriedad que raya en la devoción. Hay una innegable limitación ontológica en el ser humano, que se sabe limitado, contingente. Por eso, busca a Dios, por el deseo que tiene de ser inmortal. Y, sobre todo, de crear: la creatividad es el constitutivo esencial de la divinidad. 
Es, pues, todo un interés ontológico, metafísico. Dice Kaufmann:

Históricamente, la religión ha sido, por encima de todo, la que ha despertado y cultivado el interés ontológico del hombre, y que ha elevado la mirada de las masas a cierta idea de, por lo menos, un grado superior del ser. Ha hipostatizado en forma de dioses este ser superior, lo ha representado, de manera más o menos visible, como una posibilidad; y, en nombre de estos dioses, exigió a las masas cambiar su modo de vida, a no contentarse con una existencia en el plano fisiopsicológico, y a aspirar a algo superior (1983, p. 374).

Ante ese algo superior, ante la divinidad, el hombre expresa las cosas más difíciles, como el amor, la tristeza, el dolor y la alegría, más que lo que podría expresar a otro hombre. El discurso de Kaufmann llega a tonalidades poéticas:

En la plegaria puede alcanzarse una intensidad de devoción que posiblemente nunca podría lograrse en un diálogo con otros seres humanos. La soledad deja de ser muda y gana en dimensión. Los sentimientos apasionados, inhibidos en la charla con los demás, hallan su desfogue en las exultaciones, los agradecimientos, las lamentaciones y las acusaciones que, de pronto, encuentran oído. Lo que antes quedaba en el capullo y se secaba sin crecer, ahora florece. El alma levanta el vuelo y se remonta a lo alto (1983, pp. 374-375).

Pero esto se resiste a ser formulado con la razón. Es donde la razón encuentra sus límites. Kaufmann no es un racionalista. Señala límites a la razón, precisamente, para abordar estas cosas. La razón no alcanza a abarcar la aspiración. La aspiración sigue siendo mucho más. Más aún, llega a decir que la razón misma aspira a ese más allá. En él coinciden razón y aspiración, que parecían tan separadas: 
Si no se le cortan las alas, la razón siempre se remontará más allá de la creencia. La razón nunca puede sentirse a sus anchas en este mundo. Sobre las alas de la actividad investigadora trasciende las creencias y los hechos y todo lo que existe. Busca otra dimensión (1983, p. 378).

Pero la razón es noble, ejerce la función para la que fue creada: la crítica. Y la crítica es necesaria, aun para la religión, porque puede haber cosas en ella que sean inadecuadas. Por eso, la religión y la razón no deben separarse, deben trabajar la una para la otra.

\begin{abstract}
Ninguna religión ha tenido respeto suficiente a la razón, y algunas le han declarado la guerra. Pero si se nos hace escoger entre razón y religión, la elección es entre crítica e idolatría. Todo lo que en la religión no puede soportar la crítica no vale la pena... y esto representa mucho, pero no representa todo. Entre las cosas que permanecen está la aspiración, que es el alma de la religión (1983, p. 378).
\end{abstract}

Así, aunque nuestro autor pone en crisis todas las religiones, no tiene una actitud adversa hacia ellas. Critica la pretensión de demostrar la existencia de Dios con argumentos racionales definitivos, pues, considera que lo religioso no es susceptible de ser sujetado a la razón. También critica aspectos prácticos o morales en los que ha fallado la religión, como las persecuciones de los heréticos, las Cruzadas, la Inquisición, etcétera.

Sin embargo, resaltando más el aspecto experiencial de la religión, esto es, la experiencia mística, piensa que hay un núcleo en la religión que es el que interesa para el hombre. A pesar de que es un aspecto más bien emocional, al que llama aspiración, asegura que la razón misma tiene por sí sola esa tendencia hacia lo más elevado. 
Parece querer salvaguardar el misterio, el cual no es reducible a la razón, sino que está más del lado del sentimiento. Agrega algo importante: la filosofía misma no puede ser solo racional, necesita del sentimiento para tener vida. Es decir, el recurso al sentimiento no es privativo de la religión, sino que asimismo compete a la filosofía; y la razón no es peculio de la filosofía, pues, también la usa la religión, aunque no de manera igual, sino análoga. En ambos casos, el de la religión y la filosofía, el hombre piensa con todo su ser: intelecto y afecto.

Da la impresión de que Kaufmann, como buen filósofo existencialista, piensa en el hombre total, en todo el hombre, sin poner como único conocimiento válido el de la razón, sino que también atiende a los sentimientos (a las "otras razones", las del corazón, como diría Pascal). Es el sentimiento religioso. Yo encuentro, por ello, que nuestro autor es muy abierto; no condena sin más la religión, ni como teóricamente falsa ni como moralmente mala, sino que todo va a depender de la praxis con la que se lleve a la vida. Su origen es la vida, y no puede desligarse de ella, sino responderle a ella.

Tal es, a mi entender, la posición de Kaufmann frente a la religión y frente a la filosofía (el mismo título de su obra dice que critica tanto la religión como la filosofía). Y es que la filosofía como tal, al decir de nuestro autor, no se diferencia demasiado de la religión; ambas usan la razón y el sentimiento, la aspiración y la crítica. Solo que la filosofía está más del lado de la razón y la religión más del lado del sentimiento. Por eso, a la filosofía le toca de manera más propia ejercer la crítica por parte del hombre y a la religión el cuidar la aspiración del ser humano. No dejar que se muera, pues, cuando la deja morir, muere también ella, la religión. Veo en Kaufmann un intento de purificación del ámbito religioso, por la razón, como el que trató de hacer Nietzsche (y, desde mi punto de vista, también Marx y Freud, los tres filósofos de la sospecha). Y, por eso, he querido atender a su discurso. 


\section{REFLEXIÓN}

En seguida expongo algunas reflexiones que ese discurso me ha despertado. Es muy sugerente y, por eso, han surgido los siguientes pensamientos, que intentan hacer caso de sus reconvenciones y aprovechar la iluminación que proviene de su autenticidad frente a la religión y la filosofía.

Razón y aspiración, crítica e idolatría. La razón corre el peligro de ser mera crítica, autodestructiva a la postre, como la serpiente de los gnósticos, que se mordía la cola y se devoraba a sí misma. Pero la aspiración, sin tomar en cuenta a la razón, se vuelve idolatría, se hace dogma encarnizado, en el fondo, egolatría. Por eso, la humildad del creyente se muestra aceptando las críticas de la razón, y la honestidad del filósofo se manifiesta respetando el misterio de la experiencia religiosa, que es irreductible a su dominio y control.

Encuentro en Kaufmann una gran honestidad y, por ello, le he dedicado mi atención. Pero percibo en él una inclinación a la equivocidad, a la ambigüedad, como buen existencialista que fue. Aunque aplica la razón argumentativa para criticar los argumentos a favor de la existencia de Dios, acepta algo por el lado del sentimiento. Y es que, en definitiva, nos topamos con límites de la razón, en los cuales opera la intuición e incluso el sentimiento. Es el hombre total, y Kaufmann es, así, uno de sus defensores, a pesar de los pesares.

Por eso, únicamente quiero hacer notar que no me parece que Kaufmann haya entendido bien la analogía y que se inclina al equivocismo. Por consiguiente, declara ambiguas (es decir, equívocas) todas las expresiones sobre Dios y descarta la teología. Incluso rechaza el símbolo como lenguaje de lo divino. Parece aspirar al sentido literal, y, como no se alcanza, se desliza hacia el solo sentido alegórico, equívoco. Más bien, la analogía trata de mostrar esa 
humildad que Kaufmann pide ante Dios en el discurso religioso. Es la modesta aceptación de que no se puede hablar de Dios en sentido literal (unívocamente), pero es también la lucha denodada contra la teología negativa, contra el mero callar, porque tanto Aristóteles como Heidegger nos dicen que el hombre es el animal que habla, el que tiene logos, o al menos aspira a él. La misma analogía tiene un pathos, una tragedia, de querer decir y no alcanzar a hacerlo. Pero también es deseo que proyecta, esperanza asomada a lo que no alcanza, impulso hacia lo otro.

El equilibrio que nuestro autor quería entre la razón y la aspiración, entre la crítica y la mística, nos alecciona acerca de que la experiencia mística debe allegarse a la razón, aunque esta no sea suficiente para dar cuenta de ella, y acerca de que la teología no debe nunca separarse de la experiencia mística, so pena de volverse árida y fría. Pero es, precisamente, lo que se intenta con la analogía. Ella sirvió para expresar, de alguna manera, la experiencia mística, al menos metafóricamente, en la poesía; y también sirvió para enmarcar esa experiencia en la teología, con una teología analógica, ni teología negativa ni afirmativa, sino con la moderación y humildad que le tiene que enseñar su insuficiencia para decir lo que solo se puede mostrar: el misterio.

Así se entiende la enemistad de Kaufmann contra la teología, y su cercanía con la experiencia mística, que él acerca a la experiencia artística; él mismo fue poeta y sabe de esto. En todo caso, persiste la honestidad de nuestro autor, y se ve que exige la experiencia y la vida. Señala que cree más en los creyentes comprometidos que en los filósofos que solo son de salón. Es cuando la religión muestra ser vida intensa, autenticidad y dinamismo creativo.

Kaufmann releva mucho la creatividad, casi endiosa la creatividad, en el sentido de que la pone como el constitutivo de Dios. No 
deja de lado el amor. Crear y amar. Tal es lo que caracteriza a Dios, y es lo que el hombre desea, según aquello de la serpiente del Génesis: "Seréis como dioses". Esto puede quedar en mera tentación, en una enfermedad mental; para que esto no ocurra, el hombre se agarra de la razón, de lo que alcance a llegar hasta esa altura, y la usa para cribar, para cernir, para criticar y discernir, pues, eso se necesita tanto en la filosofía como en la religión.

Tal es el testimonio de Walter Kaufmann, especialista en Hegel y en Nietzsche, en los dos extremos: la razón y la aspiración. Pero no sucumbió ni a la sola razón y ni a la mera aspiración. Trató de conjuntarlas. Y en eso, aun sin saberlo, se mostró sumamente analógico.

De hecho, una hermenéutica analógica cumple con lo que pide Kaufmann, pues, se trata de involucrar la parte unívoca del hombre, que es la razón, con la parte equívoca de este, que es la emoción. Por supuesto que parte de la aspiración del hombre, pero también incluye la crítica de los distintos aspectos de la religión.

Si aplicamos unívocamente la razón a la religión, desaparece por asfixia, por ahogo, por excesivo estrangulamiento; si nos abandonamos equívocamente al sentimiento en la religión, esta se evapora. La aspiración, indudable en el ser humano, puede conducir a la equivocidad; la crítica que realiza la razón corre el peligro de cerrarse en la univocidad.

Kaufmann hace muy bien en poner de relieve la aspiración, el sentimiento, en la religión (y en la filosofía). Sin ella la religión se evapora, pero la filosofía también, por carecer de sentido para el hombre. Además, exige la razón, pues, sin ella la religión se desvía, y lo mismo la filosofía, por carecer de la parte referencial, de la referencia. La parte del sentido es el que hace vivir (lo necesitan tanto la religión como la filosofía), y la parte de la referencia es la que hace 
evaluar críticamente si es adecuado o no con la realidad lo que se hace tanto en la religión como en la filosofía.

La crítica es como la parte metonímica del hombre, y la aspiración es como su parte metafórica. Pues, la metáfora es sobreabundancia de sentido, mientras que la metonimia abunda en referencia. La primera opera por semejanza, y esta nos conecta con los demás; la segunda opera por contigüidad, y esta nos conecta con la realidad. Ambas son necesarias. Y la analogía las abarca a las dos, las abraza. Por eso, la analogía nos puede ayudar a encontrar y a interpretar el sentido y la referencia, lo metafórico y lo metonímico del hombre, reflejados en la religión y la filosofía.

Kaufmann se precia de haber destruido los principales argumentos que intentan probar la existencia de Dios. Es solo la parte referencial de la religión, pero falta la del sentido. En una hermenéutica analógica, ciertamente, es importante el lado argumentativo, pero no de manera unívoca. Los argumentos no tratan de probar apodícticamente la existencia de Dios, pues, no habría cabida para la fe. Tienen, por lo general, la intención de hacer razonable la existencia de Dios y, por lo mismo, creíble. Alguien que fue eminente en la lógica y en la religión, el lógico polaco I. M. Bochenski, no mucho antes de morir (en 1995) escribió un artículo que mostraba que las cinco vías de santo Tomás no son demostrativas (1989, pp. 235 y ss.). Pero hay que aceptar que hacen razonable lo que intentan, es decir, hacen ver que no es falso a priori, que no es una contradicción en los términos, que tiene cierta probabilidad o plausibilidad. En suma, que no es algo irracional.

De la misma manera, puede decirse que las objeciones o críticas a dichos argumentos, o a la religión con otros argumentos, tampoco son plenamente concluyentes. Se pueden encontrar sus puntos ciegos, como lo han hecho célebres filósofos de la religión, sobre 
todo, de corte analítico, como Richard Swinburne (2011, pp. 367 y ss.). Me parece algo muy auténtico y honesto lo que dice el filósofo analítico mexicano Guillermo Hurtado: "Repasé entonces todos los argumentos sobre la inexistencia de Dios. Pero pronto descubrí algo que me dejó helado: examinándolos con sumo cuidado ninguno de ellos me convenció, siempre hay una manera de bloquearlos en algún punto" (2005, p. 58). Así como los argumentos que intentan probar a Dios pueden ser detenidos en algún momento, lo mismo los que tratan de disprobarlo. Hay cierta paridad en ello.

Ahora bien, en una hermenéutica analógica es quizá más importante, por lo mismo, el lado de sentido que da la religión. Sin excluir el lado referencial o de referencia. Porque lo que más nos ha aportado la religión es sentido para vivir. Es lo que el propio Kaufmann llama la aspiración. La aspiración da sentido, y la crítica asegura la referencia; por eso, aconseja que la aspiración sea acompañada por la crítica. Pues bien, la religión es la guardiana de la aspiración, del sentido, y la filosofía lo es de la crítica, de la referencia. Pero, como hemos dicho, siguiendo a Kaufmann mismo, la religión sin crítica es ciega, pero la filosofía sin aspiración es vacía. Tenemos que conjuntar según su proporción a ambas, en un equilibrio analógico.

Inclusive una hermenéutica analógica estará más preocupada, en cuanto a la religión, al sentido que proporciona que a la referencia que gana. Será importante examinar la razonabilidad o credibilidad de la existencia de Dios, pero en cuanto probable o plausible, mientras que el sentido que da para vivir una existencia plena y realizada será aún más importante. Esta última es la prueba suprema, pues, ¿de qué le sirve al hombre demostrar lo que es objeto de su aspiración si no le brinda sentido? ¿No es lo que ha hecho la ciencia (el racionalismo y el empirismo) de la modernidad, y lo que ahora tanto critica la posmodernidad como algo vacío de contenido? Por 
eso, es más urgente que, después de asegurar la probabilidad o verosimilitud de lo divino, encontremos qué sentido nos señala, como las cifras de las que hablaba Jaspers. Cifras de lo divino, escritura cifrada que tenemos que descifrar, interpretar en su simbolismo. Y para ese simbolismo lo más adecuado es esa hermenéutica analógica de la que venimos hablando, pues, está pensada para interpretar precisamente el símbolo, lo simbólico, de lo que está llena la religión.

\section{CONCLUSIÓN}

La filosofía de la religión ha despertado un gran interés en varios filósofos actuales. Es impresionante el volumen conectivo en el que participaron Gadamer, Derrida, Vattimo y Trías. Han hecho tratamientos muy atendibles, pero también se ha dado esto en filósofos no tan recientes, como es el caso de Walter Kaufmann, quien fue típicamente del siglo pasado. Nacido en 1921, y muerto en 1980, se especializó en Hegel y Nietzsche, así como en el existencialismo, de modo que se podía contar como uno de los representantes de este último movimiento.

$Y$ es en la filosofía de la religión donde mejor encontramos el sitio y papel de la analogía. En efecto, ella trata nada menos de decir lo indecible, esto es, decir lo que solo se puede mostrar. Por eso, utiliza el discurso indirecto, de metáforas, símbolos, parábolas. Pero es consciente de su insuficiencia, y se llena de modestia con respecto a sí misma y sus alcances. Conoce sus límites, y los reconoce. Es solo una manera de evitar caer en el silencio de la teología negativa y en la pretensión desmesurada de la teología afirmativa; se coloca, la teología analógica, en el medio prudencial, en el abajamiento o kénosis que no renuncia al logos, a la palabra. 